\title{
Prevention of spinal injuries from diving in Slovenia
}

\author{
H Damjan and PR Turk \\ University Rehabilitation Institute, 61000 Ljubljana, Linhartova 51, Slovenia
}

\begin{abstract}
Injury of the cervical spine involving the spinal cord such as results from diving into shallow water causes very severe disability. In spite of progress in medical science, results of the treatment and rehabilitation of such patients are not satisfactory. Every effort should be undertaken to give young swimmers, the most frequent victims of diving injuries, proper instructions to prevent spinal cord injury. A broadly conceived national prevention programme, developed under the catch-phrase 'Do Not Jump into the Unknown', has been under way in Slovenia during the past 3 years, and has been promoted in collaboration with the Health Protection Institute of Slovenia. In these years the number of new spinal cord injuries decreased (one-two per year), but it is too early to conclude that this is the result of the prevention activities. But it is obvious that knowledge of this type of injury is now much more widespread.
\end{abstract}

Keywords: diving; cervical spinal injury; tetraplegia; prevention; Slovenia

\section{Introduction}

Slovenia is a small country $\left(20.25 / \mathrm{km}^{2}\right)$; there are 1996000 inhabitants. In spite of its small size, Slovenia is characterized by the diversity of its relief, numerous rivers, lakes, the sea, spas, and other bathing places. This is why bathing and swimming, particularly during the summer, are the most popular form of recreation. Slovenia has a well established nationwide programme of swimming instruction. The young learn to swim at an early age. Most school-age children participate in an organized swimming course. During the elementary and secondary school years, they have at least two swimming courses. Drowning accidents resulting from being unable to swim are on the decrease. However, besides swimming in the strict sense of the word, little attention is given to other aspects of this activity. Swimmers do not appear to be well informed regarding injuries that may occur during bathing and swimming. They are too often victims of various types of injury, the most frequent among them being injury of the cervical spine resulting from diving into shallow water.

Injury to the cervical spine and spinal cord from diving into shallow water often causes a severe disability. ${ }^{1-6}$ This usually occurs during bathing and recreational swimming, by an incautious, badly performed jump head-first into water of unknown depth. ${ }^{7-9}$ The victims of such accidents are mostly young people. .,3,7 $^{2}$ The injury usually results in severe tetraplegia, causing a handicap to the patient, to his or her family, as well as to society as a whole..$^{8-10}$ Most of the injured individuals state that before the accident they were not actually aware that such an injury might occur, which means that ignorance plays an important part in accidents of this type.
The absolute number of such injuries in Slovenia is not high, seven per year at the most. However, the devastating consequences of such accidents, involving predominantly young people, prompted us to embark upon a prevention project with the aim of reducing the number of new injuries of this kind.

The planning of an efficient prevention programme, having a bearing on the nation as a whole, involves the following procedures: ${ }^{11,12}$

1 perform an epidemiological analysis to identify the population at risk and its characteristics;

2 state the cause of this type of injury and determine preventive measures;

3 design short term and long term multidisciplinary prevention programmes to be applied in practice;

4 select subjects in charge of an ongoing national programme.

\section{Epidemiological analysis of the situation in Slovenia prior to the institution of a prevention programme}

Precise data on the number of spinal cord injuries (SCI) from diving in Slovenia are not readily available. Most of the patients with spinal cord injuries are subject to rehabilitation programmes at the University Rehabilitation Institute in Ljubljana. Forty nine of the patients treated at the Ljubljana Rehabilitation Institute between 1970 and 1992 had injuries of the cervical spine and spinal cord resulting from diving, the largest number in a season being seven.

We analysed the SCI population. The analysis revealed similar facts to those noted in other countries, although on substantially larger research samples. In 
$48 \%$ of the cases (Figure 1), the age of the injured ranged from 15 to 19 years, and in no less than $83 \%$ from 14 to 24 years. Ninety two per cent of the injured were males. Seventy six per cent of the injuries affected spinal levels between the fourth cervical and the sixth cervical vertebra. In $96 \%$ (Figure 2), the injury resulted in a partial, though fairly severe paralysis of the hands and complete paralysis of the legs, ie tetraplegia. Eighty six per cent (Figure 3 ) of the accidents happened at the peak of the swimming season, from June to August. Records of the exact locality of the accidents are mostly incomplete. The majority of the accidents occured in rivers and lakes, fewer in the sea, and only a small number happened in swimming pools. Most of the accidents occured outside organised bathing areas.

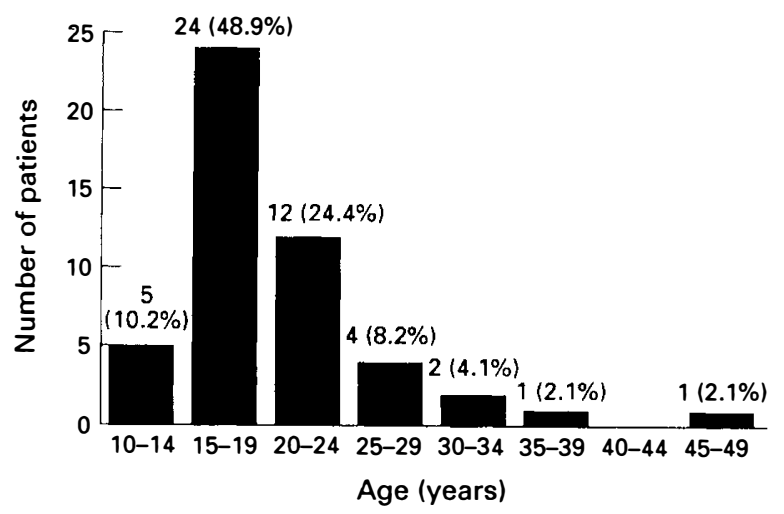

Figure 1 Age of patients

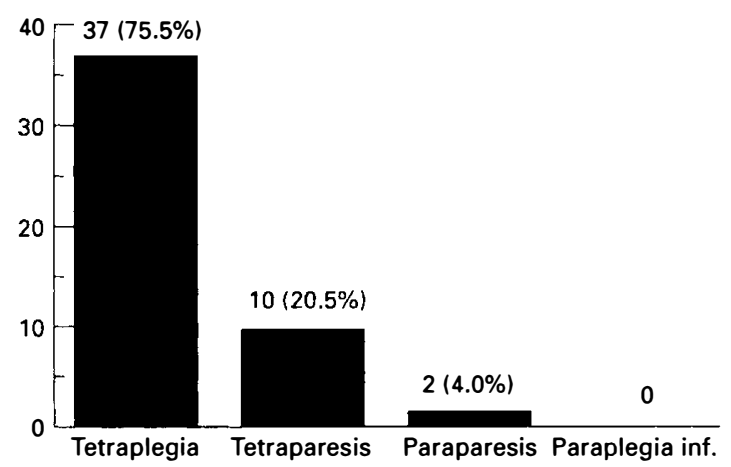

Figure 2 Resulting disability

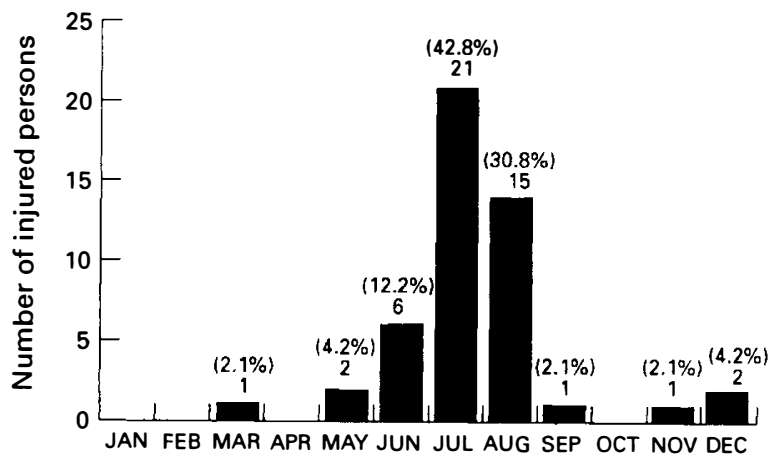

Figure 3 Incidence of diving injuries by months of the year

\section{Mechanism of the diving injury}

Injury of the cervical spine and spinal cord results from diving into shallow water where the head strikes the bottom or an obstacle in the water ${ }^{2,5,13}$ The forces of the impact are transferred, via the skeleton, onto the cervical spine, and when the forces exceed the absorbing capacity of the surrounding tissues, certain vertebrae are dislocated and may be fractured. In most cases, the axial force is complemented by a flexion force. The massive axial force, acting upon the neck in flexion, results in a crush fracture of cervical vertebrae. This is followed by dislocation of fragments toward the posterior aspect of the spinal canal. The fragments injure the spinal cord, particularly its anterior part. The most frequently damaged vertebrae are $\mathrm{C} 5$ or $\mathrm{C} 6 .{ }^{3,4,7,8}$ At these vertebral levels, the spinal cord injury results in tetraparesis or tetraplegia, respectively. In spite of long-lasting treatment and rehabilitation, the patient remains wheelchair bound, requiring the assistance of another person to attend to most of his/her basic daily needs.

\section{Planning a prevention programme}

The mechanism of the diving injury and its consequences point to the possibility and necessity of planning preventative measures. Our goal is to prevent such injuries, since treatment and rehabilitation fail to give satisfactory results. ${ }^{14}$ An epidemiological analysis shows the most likely part of the population for which a prevention programme is required. In planning an efficient prevention programme, it is necessary to

1 identify the population that mainly requires preventative measures;

2 determine the modes of preventative measures;

3 determine who should be in charge of the programme.

The message of the prevention program must reach

- youth

- teachers

- medical workers

- parents.

Modes of preventative measures should be

- lectures

- posters

- brochures

- videos

- radio and television broadcasts

- newspaper articles.

Groups and others in charge of the programme should be

- University Rehabilitation Institute

- Health Protection Institute

- Faculty of Sports

- Teachers

- Institute of Education.

Regarding the University Rehabilitation Institute, 
we conceived this programme in a broad sense and as a long term project which should have a bearing on the Slovenian population as a whole and should be of national importance. We therefore combined our efforts with the central Slovenian preventative institution, the Health Protection Institute of Slovenia. As a result of this collaboration, a prevention programme has been developed and has been in action for 3 years. It is promoted with the catch-phrase 'Do Not Jump into the Unknown'. The principal motto of the programme is the education of young swimmers.

Safe bathing is advice that every swimmer must appreciate when first learning to swim. The aim of the programme is to encourage cautious swimmers, acquainted with possible bathing and swimming injuries and their results, and to teach how to avoid accidents which can have severe consequences.

The preventative activities are divided into (1) a short term programme and (2) a long term programme.

\section{Short term programme}

This takes the form of a yearly campaign before and during the main swimming season, and includes

1 producing posters with a warning inscription and placing them in public baths, schools, medical institutions, etc;

2 preparing and distributing a brochure with illustrations and textual information on injuries and preventative measures;

3 producing notices with rules for the safe conduct when bathing and diving;

4 production of a video on preventative measures and broadcasting information on national TV programmes before and during the principal bathing season, several times a week, at the times of the most widely watched transmissions;

5 publication of articles, before the swimming season, on preventative topics, in adult and in children's papers and magazines;

6 discussing preventative topics in children's and other broadcasts on the radio and television;

7 information campaigns, before the swimming season, at schools (eg during lessons in gymnastics and during preventative medical check-ups).

\section{The long term programme}

\section{This includes}

1 the education of staff engaged in teaching young people, and directly involved in giving swimming lessons. In this way information on cervical spine injuries becomes an integral part of the regular training programme for professors of sport at the Faculty of Sports, teachers of sports at the Institute of Education, and all programmes of additional education for teachers of sports and swimming teachers;

2 education of officers in charge of health care education, responsible for putting the programme of health care education into practice;

3 education of young people during their school years and at swimming courses. This should happen (1) during the first swimming course; (2) in the 4th class of elementary school, when a swimming course is organized during school-in-nature lessons; (3) in the 7 th class, during the first-aid course; and (4) in secondary school, during lessons in gymnastics.

Some auxiliary instruction material has been prepared to assist those in charge of the long term programme. It is used by teachers and health care officers as an aid in giving information on the subject and is made up of the following components:

1 a set of transparent foils dealing with the ways in which people may sustain the injury and the results of $\mathrm{SCI}$, including suggestions on preventative measures;

2 a 10-minute film providing information on SCI and relevant preventative measures, and introducing two actual injured individuals;

3 a 20 -minute radio broadcast on prevention topics, in collaboration with two injured individuals;

4 a poster with textual and illustrative contents, to promote the vital prevention of neck injuries.

The materials are distributed by the Health Protection Institute of Slovenia.

\section{Conclusions}

It is difficult to evaluate the efficiency of any prevention programme as it is virtually impossible to draw a line between an incidentally lower number of injuries and a smaller number of injuries that could result from duly considering preventative measures. ${ }^{12}$ Our prevention programme is a long term project. Its foremost objective is to teach young people to act cautiously while bathing or swimming. The population as a whole might be better informed of the injuries and more attentive to preventative measures within about 5 years. Their awareness of the problem will be studied, by a questionnaire, 5 years after the introduction of preventative activities, and will cover the most vulnerable part of the population and the teaching staff. It will concentrate upon our knowledge of the problem and the source of information.

We wish to add that in the past 2 years the number of new diving injuries cases is in fact on the decrease. In the last 3 years we only had one or two spinal cord injuries resulting in tetraplegia from diving. Knowledge about the possibility of spinal injury is obviously wider, especially in teachers of swimming. Our efforts have borne fruit it would appear. Certain new sports such as, dragon-flying, gliding and sky diving can result in serious spinal trauma. Physical fitness itself is an important factor in helping to prevent certain spinal injuries in sportspersons. It is therefore necessary to start suitable preventative programmes in several realms of life, including swimming and diving.

\section{References}

1 Donovan WH, Bedbrook G. Comprehensive management of spinal cord injury. Clin Symp 1982; 34: 1-36. 
2 Good RP, Nickel VL. Cervical spine injuries resulting from water sports. Spine 1980; 5: 502-506.

3 Steinbruck K, Paeslack V. Analysis of 139 spinal cord injuries due to accidents in water sports. Paraplegia 1980; 18: 86-93.

4 Green BA, Gabrielsen MA, Hall WJ, O'Heir J. Analysis of swimming pool accidents resulting in spinal cord injury. Paraplegia 1980 ; 18: $94-100$.

5 Toscano J. Prevention of neurological deterioration before admission to a spinal cord injury unit. Paraplegia 1988; 26: 143-150.

6 Perovitch M. Advancements in the neuroimaging of the spinal cord. Paraplegia 1987; 25: 244-249.

7 Frankel HL, Montero FA, Penny PT. Spinal cord injuries due to diving. Paraplegia 1980; 18: 118-122.

8 Griffiths ER. Spinal injuries from swimming and diving treated in the spinal department of Royal Perth rehabilitation hospital: 1956-1978. Paraplegia 1980; 18: 109-117.

9 Biering-Sorensen F, Pedersen V, Clausen S. Epidemiology of spinal cord lesions in Denmark. Paraplegia 1990; 28: 105-118.

10 Stover SL, Fine PR. The epidemiology and economics of spinal cord injury. Paraplegia 1987; 25: 225-228.

11 Yeo JD, Walsh J. Prevention of spinal cord injuries in Australia. Paraplegia 1987; 25: 221-224.

12 Rose G. Epidemiology and health care planning. J $R$ Soc Med 1986; 79: 631-633.

13 Green BA, Eismont FJ, O'Heir JT. Pre-hospital management of spinal cord injuries. Paraplegia 1987; 25: 229-238.

14 Houk VN, Thacker SB. The centers for disease control program to prevent primary and secondary disabilities in the United States. Public Health Rep 1989; 104: 226-231. 